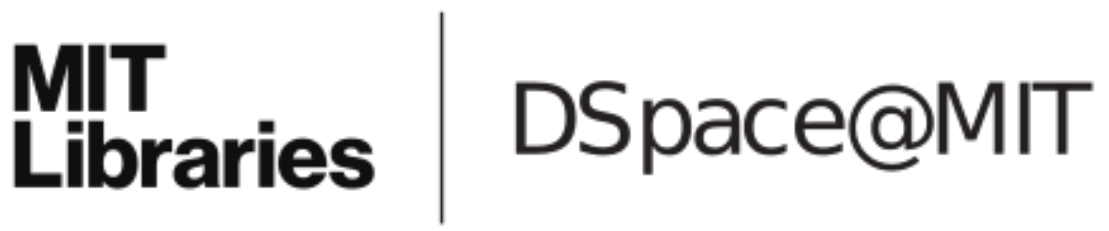

\author{
MIT Open Access Articles
}

Synthesis of Pyrroles through the $\mathrm{CuH}$ Catalyzed Coupling of Enynes and Nitriles

The MIT Faculty has made this article openly available. Please share how this access benefits you. Your story matters.

Citation: Zhou, Yujing et al., "Synthesis of Pyrroles through the CuH-Catalyzed Coupling of Enynes and Nitriles." Journal of the American Chemical Society 142, 22 (June 2020): 9908-14 (C)2020 Authors

As Published: https://dx.doi.org/10.1021/JACS.0C03859

Publisher: American Chemical Society (ACS)

Persistent URL: https://hdl.handle.net/1721.1/129424

Version: Original manuscript: author's manuscript prior to formal peer review

Terms of use: Creative Commons Attribution-Noncommercial-Share Alike 


\title{
Synthesis of Pyrroles Through the CuH-Catalyzed Coupling of Enynes and Nitriles
}

\author{
Yujing Zhou, ${ }^{1}$ Lin Zhou, ${ }^{2}$ Luke T. Jesikiewicz, ${ }^{2}$ Peng Liu,,${ }^{*}$ and Stephen L. Buchwald*,1 \\ ${ }^{1}$ Department of Chemistry, Massachusetts Institute of Technology, Cambridge, Massachusetts 02139, United States \\ ${ }^{2}$ Department of Chemistry, University of Pittsburgh, Pittsburgh, Pennsylvania 15260, United States
}

\section{Supporting Information Placeholder}

ABSTRACT: Herein, we describe an efficient method to prepare polysubstituted pyrroles via a copper-hydride $(\mathrm{CuH})$-catalyzed enyne-nitrile coupling reaction. This protocol accommodates both aromatic and aliphatic substituents and a broad range of functional groups, providing a variety of N-H pyrroles in good yields and with high regioselectivity. We propose that the $\mathrm{Cu}$-based catalyst promotes both the initial reductive coupling and subsequent cyclization steps. Density functional theory (DFT) calculations were performed to elucidate the reaction mechanism.

Pyrroles are one of the most prevalent fivemembered heterocycles, and are present in a large number of natural products, ${ }^{1}$ pharmaceuticals, ${ }^{2}$ and functional materials. ${ }^{3}$ In addition, they are valuable and useful building blocks in the preparation of complex molecules. $^{4}$ Consequently, numerous synthetic strategies have been developed to access this important class of compounds. Traditional approaches, including the Knorr, ${ }^{5}$ Hantzsch, ${ }^{6}$ and Paal-Knorr reactions, ${ }^{7}$ allow for the construction of polysubstituted pyrroles through the condensation of carbonyl compounds and amines (Figure 1a). The conditions employed in these examples, such as high reaction temperatures and the use of strong acids to facilitate the initial condensation, often result in limited scope and functional group compatibility. Recently, numerous methods, including multicomponent reactions $^{8}$ and transition-metal-catalyzed couplings, ${ }^{9}$ have been established to produce pyrroles under relatively mild conditions with better control of regioselectivity. Despite these advances, highly functionalized starting materials are often required, (e.g., iminoallenes, alkynyl aziridines, or azides), which limits the range of accessible products. Further, many existing strategies necessitate the use of substrates with protected nitrogens, which must be first installed and subsequently removed or exchanged after the assembly of the pyrrole ring, sig- nificantly decreasing the efficiency of the process. A complementary strategy to access unprotected pyrroles from readily available starting materials that operates under mild conditions would thus be of significant utility.

(a) Classic approaches to access polysubstituted pyrroles

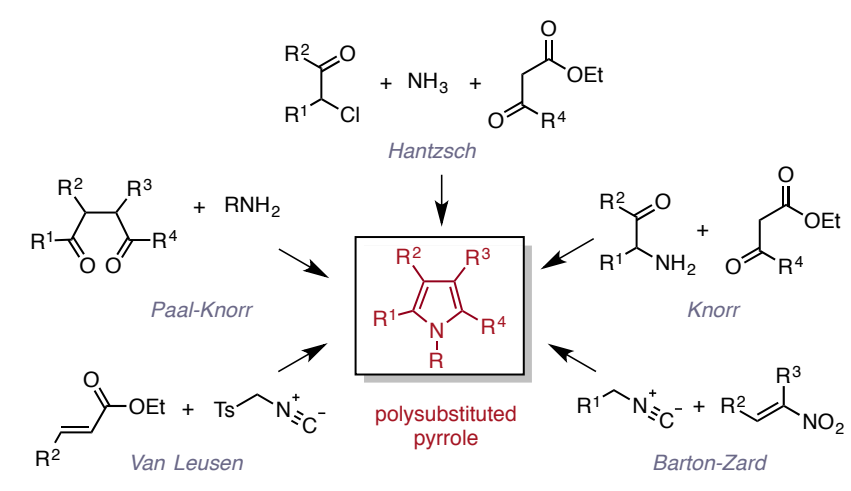

(b) CuH-catalyzed asymmetric enyne-ketone coupling reaction

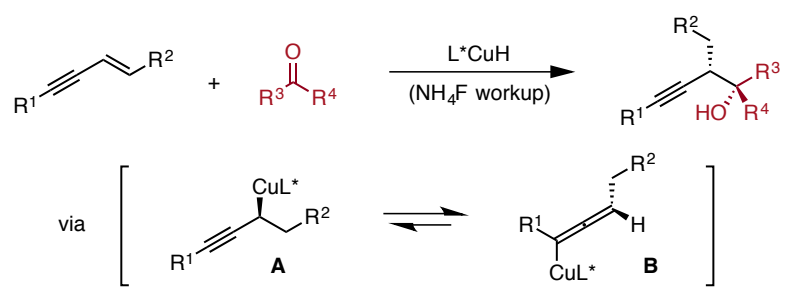

(c) Synthesis of pyrroles via CuH-catalyzed enyne-nitrile coupling (this work)

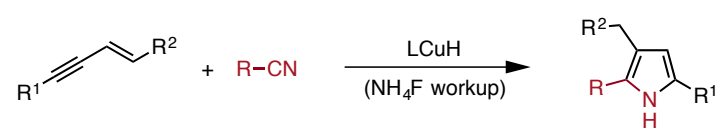

Figure 1. (a) Classic approaches to access polysubstituted pyrroles; (b) CuH-catalyzed enyne-ketone and (c) enynenitrile coupling reactions (this work).

Over the past few years, $\mathrm{CuH}$ catalysis has emerged as a useful and robust technique for olefin hydrofunctionalization. ${ }^{10}$ In these reactions, an underlying concept is the generation of nucleophilic alkyl copper intermediate from the reaction of a ligated copper hydride species 
and an unsaturated hydrocarbon. In this way, widely available and stable olefins can serve as surrogates for traditional organometallic reagents. By changing the supporting ligand, the reactivity of the corresponding alkyl copper species can be modulated. ${ }^{11}$ Furthermore, the mildness of $\mathrm{CuH}$ reaction conditions enables the use of substrates containing sensitive functional groups that are incompatible with many preformed organometallic reagents (e.g., Grignard and alkyllithium reagents). We recently disclosed a $\mathrm{CuH}$-catalyzed asymmetric addition reaction to ketones (Figure $1 \mathrm{~b}$ ), ${ }^{10 \mathrm{e}}$ in which conjugated enynes were employed as precursors to the key nucleophilic propargyl- (A)/allenylcopper intermediates (B). The reactivity manifested by in situ generated species A and $\mathbf{B}$ caused us to survey their reactions ${ }^{12}$ with other readily available electrophiles. ${ }^{13}$ Herein, we report the unexpected formation of polysubstituted pyrroles via a $\mathrm{CuH}$-catalyzed coupling reaction of 1,3-enynes and nitriles (Figure 1c). This process features mild reaction conditions and demonstrates excellent functional group compatibility, allowing the access to free $\mathrm{N}-\mathrm{H}$ pyrroles with a wide range of substitution patterns from commercially available nitriles and easily accessible enynes. ${ }^{14}$

Table 1. Evaluation of Reaction Conditions for $\mathrm{CuH}-$ Catalyzed Enyne-Nitrile Coupling Reactions ${ }^{a}$

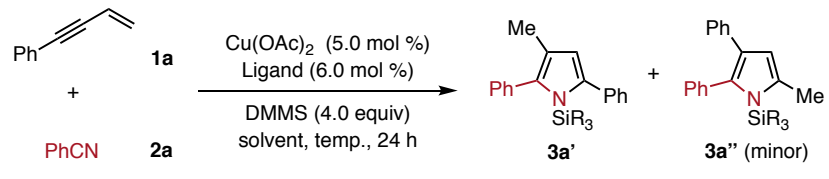

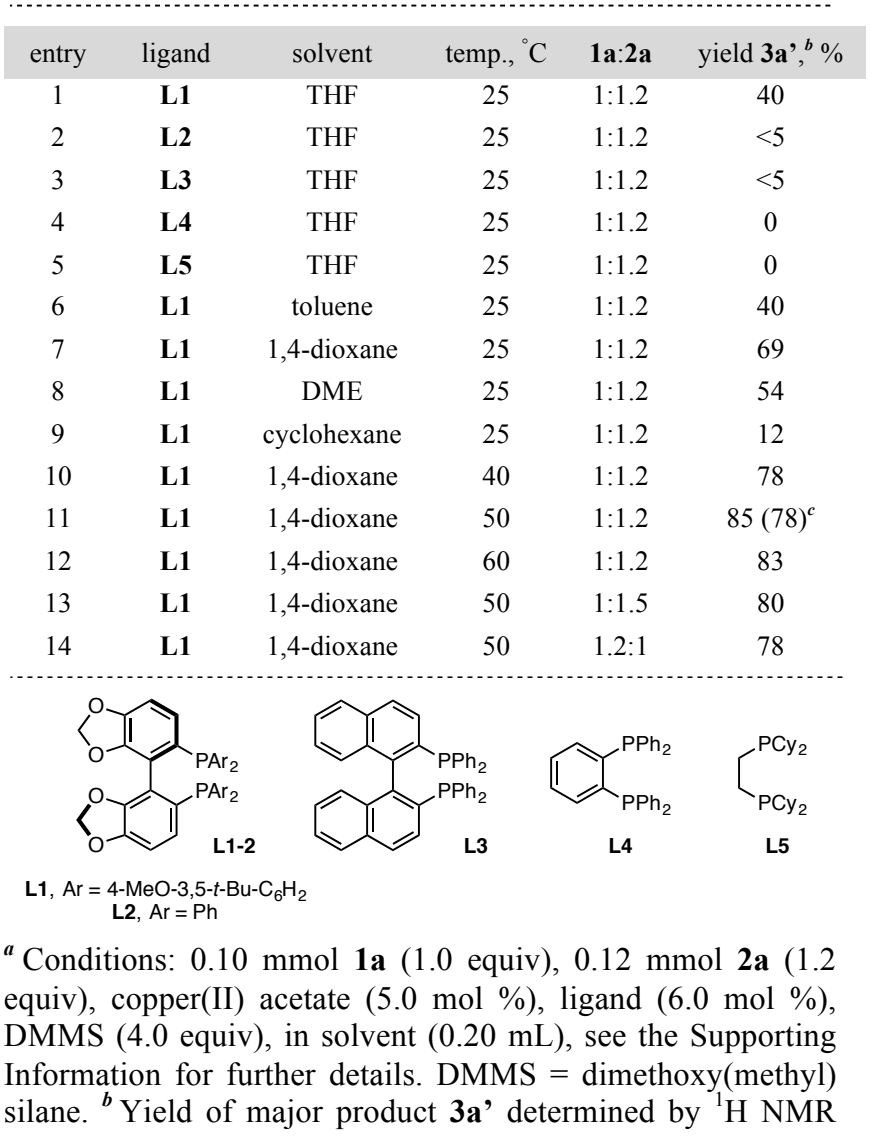

using 1,1,2,2-tetrachloroethane as the internal standard. ${ }^{c}$ Isolated yield of $\mathrm{N}-\mathrm{H}$ pyrrole on $0.50 \mathrm{mmol}$ scale after $\mathrm{NH}_{4} \mathrm{~F}$ workup.

The reaction conditions were optimized using enyne 1a and benzonitrile 2a as the model substrates (Table 1). The $N$-silylated trisubstituted pyrrole 3a' was obtained in $40 \%{ }^{1} \mathrm{H}$ NMR yield when DTBM-SEGPHOS (L1) was employed as the supporting ligand (Table 1, entry 1). Commonly used bisphosphine ligands, including SEGPHOS (L2), BINAP (L3), dppbz (L4), and DCyPE (L5), all failed to promote the desired transformation under the same conditions (Table 1, entries 2-5). Subsequent screening of reaction solvents indicated that the use of 1,4-dioxane was best, affording the pyrrole in $69 \%$ NMR yield (Table 1, entries 6-9). Considering the lower reactivity of nitriles toward the nucleophilic addition of organometallic reagents compared to carbonyl compounds, we reasoned that elevated temperature might be beneficial to promote the desired reaction. We found that $50{ }^{\circ} \mathrm{C}$ was optimal for this coupling process, and the ${ }^{1} \mathrm{H}$ NMR yield of the pyrrole product was further improved to $85 \%$ (Table 1, entries 10-12). Finally, examining different ratios of two starting materials revealed that the use of a slight excess of nitrile provided the best result for this transformation (Table 1, entries 13 and 14). It is worth mentioning that the formation of a minor regioisomer 3a" was also observed. The ratio of two products (3a': 3a"' $=8: 1$ ) was not significantly affected by variation of the reaction conditions.

Table 2. Substrate Scope of Aryl-Substituted Enynes ${ }^{a}$ 

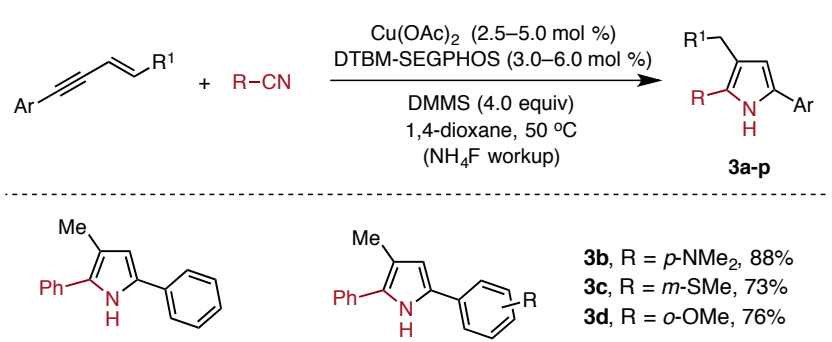

3b, $\mathrm{R}=p-\mathrm{NMe}_{2}, 88 \%$ 3c, $\mathrm{R}=m-\mathrm{SMe}, 73 \%$ 3d, $\mathrm{R}=0-\mathrm{OMe}, 76 \%$

3a, $76 \%$
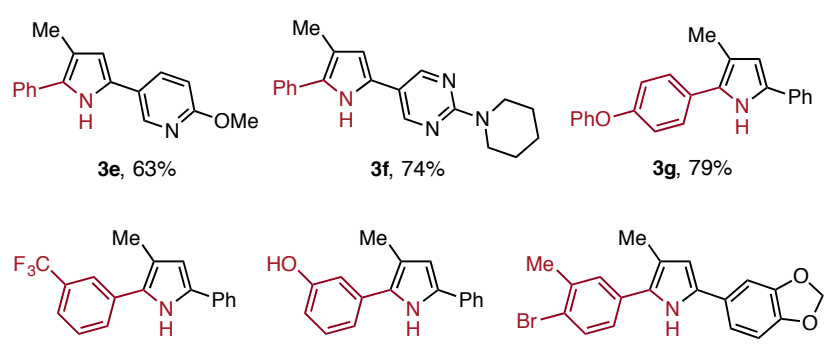

3h, $70 \%$

3i, $44 \%$

3j, $63 \%$

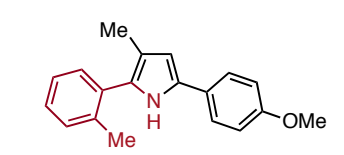

3k, $79 \%$

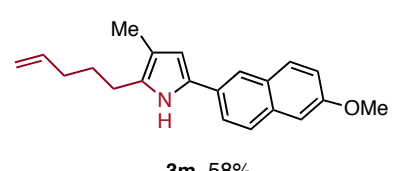

$3 \mathrm{~m}, 58 \%$

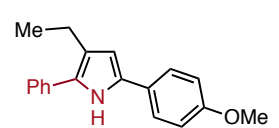

3o, $68 \%$

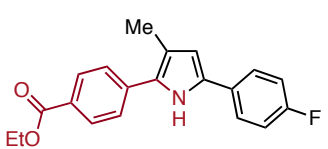

3I, $58 \%$

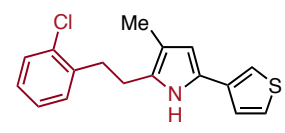

3n, $53 \%$

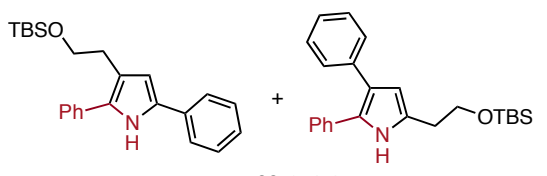

$3 p+3 p ', 68 \%, 1: 1 r r$

${ }^{a}$ All yields represent average isolated yields of two runs, performed on $0.50 \mathrm{mmol}$ scale. See the Supporting Information for detailed conditions. $\mathrm{rr}=$ regioisomeric ratio. ${ }^{15}$

With the optimized conditions for the pyrrole synthesis established, the reactivity of aryl-substituted enynes was first evaluated (Table 2). A variety of enynes with different substitution patterns on the aryl ring were converted to desired pyrrole products in good yields (3b-d). Moreover, substrates containing heterocycles, such as a pyridine (3e), a pyrimidine (3f), and a thiophene (3n), were also coupled with similar levels of efficiency. We observed that aromatic substrates with both electrondonating (3g) and -withdrawing groups $(\mathbf{3 h}, \mathbf{3 l})$ were good coupling partners. Aliphatic nitriles, typically less reactive compared to their aromatic counterparts, were also found to successfully engage in this transformation $(\mathbf{3 m}, 3 \mathbf{n})$, providing the corresponding 2,3-dialkyl, 5arylsubstituted pyrroles with moderate yields. Because of the mildness of the reaction conditions, a wide array of functional groups, such as a phenol (3i), an aryl bromide (3j), an ethyl ester (3i), a terminal olefin $(\mathbf{3 m})$, an aryl chloride (3n), and a silyl-protected alcohol (3p), were all well accommodated. Additionally, internal enynes are generally more challenging substrates, since the barrier of hydrocupration step is higher for the sterically more hindered double bond. ${ }^{11 a}$ Using this catalytic system, internal enynes were successfully coupled to benzonitrile, providing the desired products with good efficiency $(\mathbf{3 o}, \mathbf{3 p})$, although diminished regioselectivity was observed in some cases (3p).

Table 3. Substrate Scope of Alkyl-Substituted Enynes. ${ }^{a}$
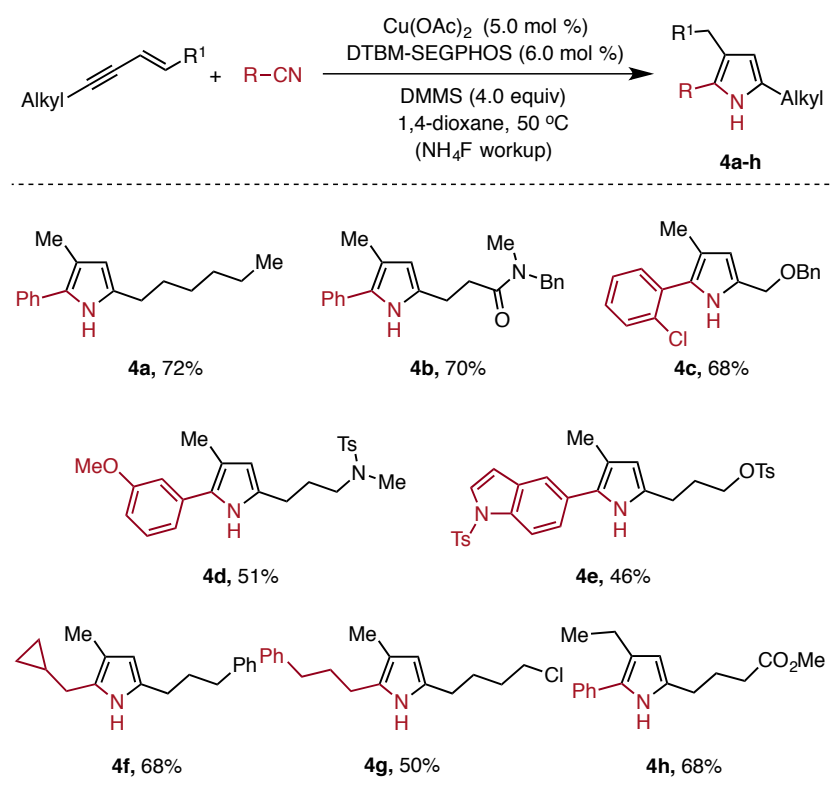

${ }^{a}$ All yields represent average isolated yields of two runs, performed on $0.50 \mathrm{mmol}$ scale. See the Supporting Information for detailed conditions.

We next focused our efforts on investigating the ability of alkyl-substituted enynes to participate in this coupling reaction. As shown in Table 3, an assortment of alkyl enynes underwent the desired transformation with good efficiency. Importantly, various functional groups remained intact under the current conditions, including a tertiary amide (4b), a benzyl protected alcohol (4c), a sulfonamide (4d), an alkyl tosylate (4e), an aryl chloride (4c), an alkyl chloride (4g), and a methyl ester (4h). Moreover, both aromatic and aliphatic nitriles were found to react well with these enynes $(\mathbf{4 f}, \mathbf{4 g})$. Finally, we demonstrated that an alkyl-substituted internal enyne was a competent coupling partner as well, affording the desired product $4 \mathrm{~h}$ with good yield and regioselectivity.

Scheme 1. CuH-Catalyzed Intramolecular Enyne-Nitrile Coupling Reaction.

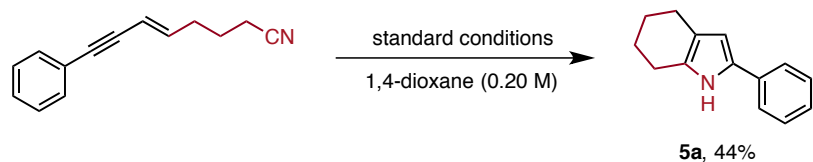

This CuH-catalyzed enyne-nitrile coupling could be performed in an intramolecular fashion by using a substrate containing both an enyne and a pendant nitrile. Under the standard conditions with decreased reaction concentration, the corresponding pyrrole 5a was prepared in $44 \%$ isolated yield (Scheme 1). 
Based on previously developed methods and past mechanistic studies, we proposed a plausible reaction mechanism outlined in Figure 2. First, a propargylcopper intermediate II could be generated from the hydrocupration of enyne 1a with a bisphosphine-ligated $\mathrm{CuH}$ species (I). Rapid 1,3-isomerization of II might lead to the formation of a thermodynamically more stable allenylcopper isomer III, which would then undergo a nucleophilic addition reaction with benzonitrile $\mathbf{2 a}$ via a six-membered transition state, providing imine intermediate IV. Subsequent ring closure ${ }^{16}$ of IV followed by 1,5-H shift and $\sigma$-bond metathesis with hydrosilane could produce the desired pyrrole product in a silylated form, while regenerating $\mathrm{CuH}$ catalyst $\mathbf{I}$. A pathway involving propargyl copper intermediate II that reacts to form imine species VII (Figure 2, inner cycle), followed by cyclization to VIII would produce the minor regioisomer 3a".

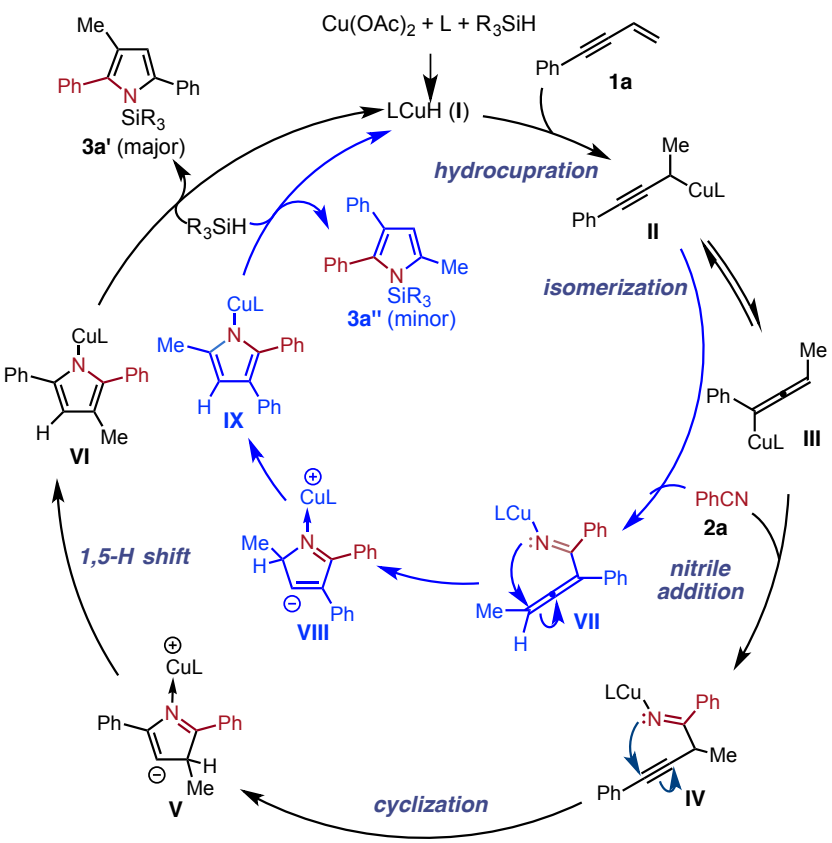

Figure 2. Proposed catalytic cycle.

\section{A. Calculated reaction energy profile}

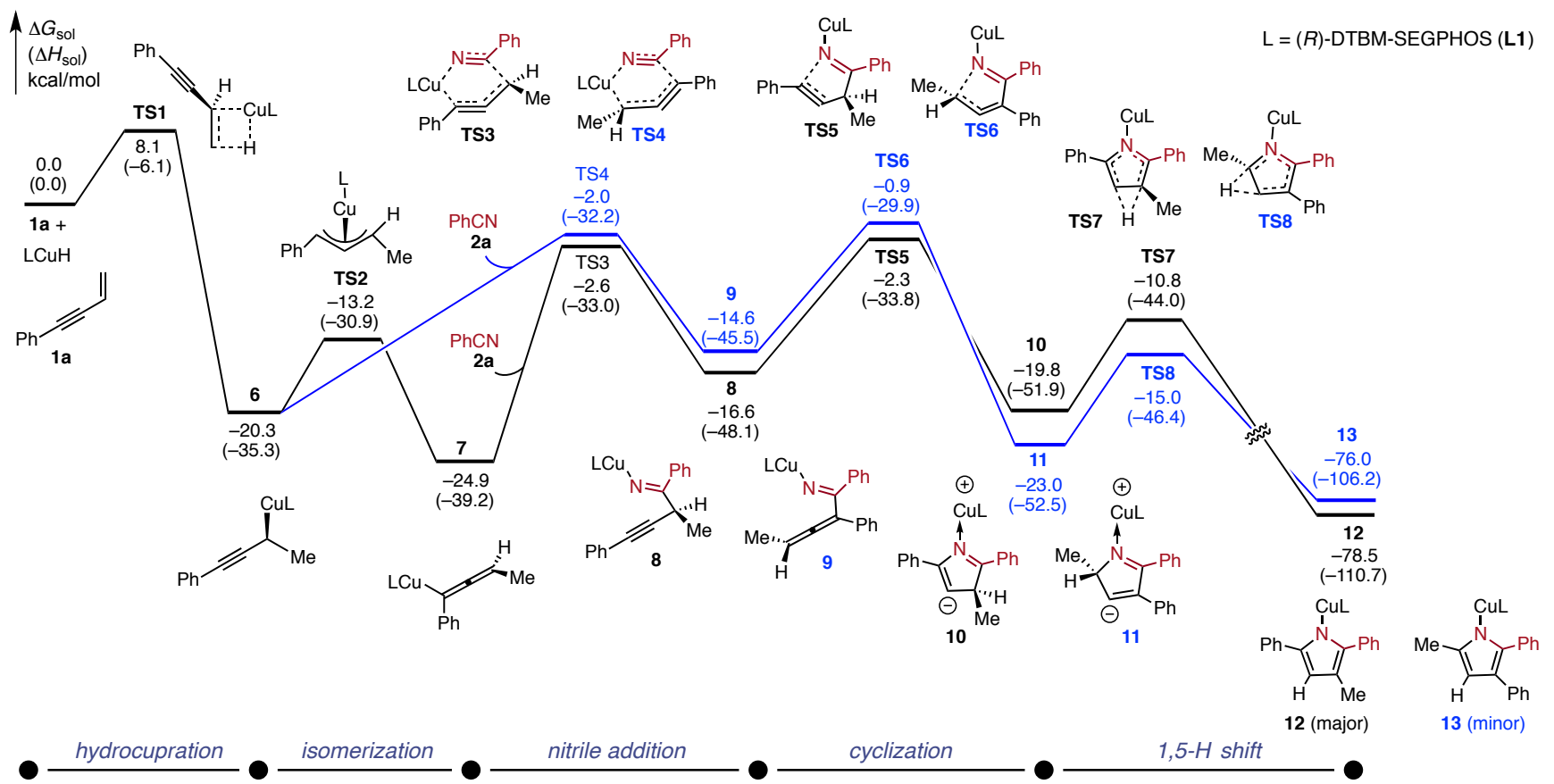

DFT calculations were performed at the M06/SDD-6-311+G(d,p)/SMD(1,4-dioxane)//B3LYP/SDD-6-31G(d) level of theory.

B. Nitrile addition transition states (DTBM-SEGPHOS ligand omitted for clarity)

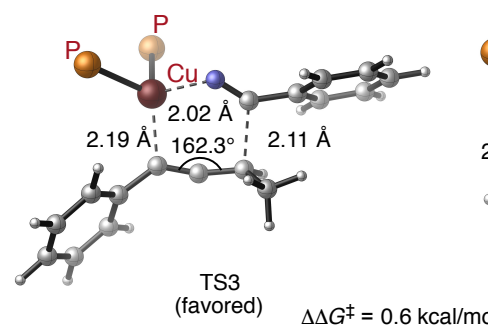

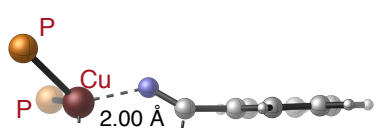
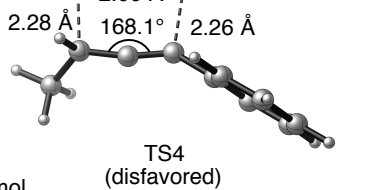

C. Cyclization transition states

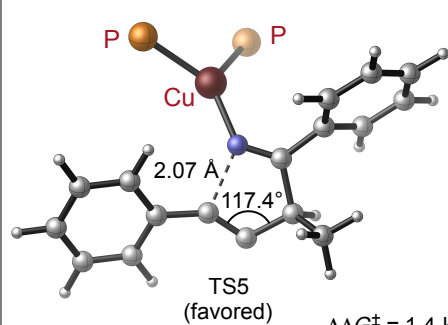

$\Delta \triangle G^{\ddagger}=1.4 \mathrm{kcal} / \mathrm{mol}$

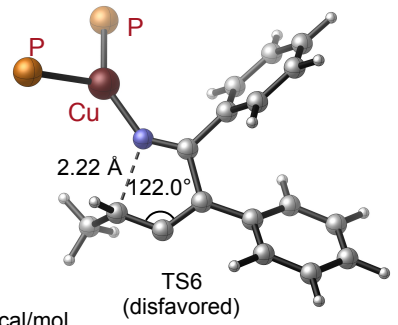

Figure 3. Reaction energy profile and transition state structures of the $\mathrm{CuH}$-catalyzed coupling of enyne 1a and nitrile 2a.

We performed density functional theory (DFT) calculations to validate the proposed mechanism and to investigate the origin of the observed regioselectivity
(Figure 3). Consistent with previous DFT studies, ${ }^{17}$ the hydrocupration of enyne (TS1) and the subsequent 1,3$\mathrm{Cu}$ shift (TS2) are both exothermic and have relatively 
low barriers. The addition of the allenyl- and propargylcopper intermediates to the nitrile occur via sixmembered cyclic transition states (TS3 and TS4, respectively). ${ }^{18}$ The resulting $\mathrm{Cu}$-imine species (8 and 9) undergo facile cyclization via TS5 and TS6 to form $3 H$ pyrrol-4-yl and 2H-pyrrol-3-yl anions (10 and 11), respectively, which upon 1,5-H shift yield the more stable 1-pyrrolylcopper species $\mathbf{1 2}$ and $\mathbf{1 3}$. The computed natural population analysis (NPA) atomic charges indicate that charge transfer from $\mathrm{Cu}$ facilitates the cyclization (see Figure S2 in the Supporting Information). It is conceivable that a small amount of Lewis acidic copper species could be formed under the experimental conditions ${ }^{19}$ which will further accelerate this nucleophilic cyclization process via coordination with the alkyne or allene to enhance the electrophilicity of the $\pi$ bond $^{20}$ (see the Supporting Information for the Lewis-acid promoted cyclization pathway). The nitrile addition and cyclization transition states leading to the major regioisomer (TS3 and TS5) are both more stable than corresponding transition states to the minor regioisomer (TS4 and TS6). Both TS4 and TS6 are destabilized by steric repulsions between the two adjacent phenyl groups about the forming $\mathrm{C}-\mathrm{C}$ bond, which is constrained to a syn-periplanar conformation in the planar cyclic transition states.

In conclusion, we have developed a $\mathrm{CuH}$-catalyzed enyne-nitrile coupling reaction that utilizes readily available building blocks to synthesize polysubstituted pyrroles. Both aromatic and aliphatic substrates were successfully engaged under the standard conditions, thus allowing the construction of pyrroles featuring diverse substitution patterns and functional groups with good efficiency. DFT calculations elucidated the mechanism and suggested the origins of regioselectivity. Studies on $\mathrm{CuH}$-catalyzed reactions for the preparation of other heterocycles are currently ongoing.

\section{ASSOCIATED CONTENT}

Supporting Information. The Supporting Information is available free of charge on the ACS Publications website. Experimental procedures and characterization data for all compounds (PDF).

\section{AUTHOR INFORMATION}

\section{Corresponding Author}

*pengliu@pitt.edu

*sbuchwal@mit.edu

Notes

The authors declare no competing financial interest.

\section{ACKNOWLEDGMENT}

Research reported in this publication was supported by the National Institutes of Health (R35-GM122483, R35GM128779) and China Scholarship Council (No.201906180037). The content of this communication solely reflects the research and opinion of the authors and does not necessarily represent the official views of the NIH.
Y.Z. acknowledges Bristol-Myers Squibb for a fellowship in synthetic organic chemistry. We are grateful to Drs. Richard Liu, Scott McCann, Alex Schuppe, and Christine Nguyen for advice on the preparation of this manuscript. DFT calculations were performed at the Center for Research Computing at the University of Pittsburgh and the Extreme Science and Engineering Discovery Environment (XSEDE) supported by the NSF.

\section{REFERENCES}

(1) (a) Khajuria, R.; Dham, S.; Kapoor, K. K. Active Methylenes in the Synthesis of a Pyrrole Motif: An Imperative Structural Unit of Pharmaceuticals, Natural Products and Optoelectronic Materials. RSC $A d v$. 2016, 6, 37039-37066. (b) Young, I. S.; Thornton, P. D.; Thompson, A. Synthesis of Natural Products Containing the Pyrrolic Ring. Nat. Prod. Rep. 2010, 27, 1801-1839. (c) Fürstner, A. Chemistry and Biology of Roseophilin and the Prodigiosin Alkaloids: A Survey of the Last 2500 Years. Angew. Chem. Int. Ed. 2003, 42, 3582-3603. (d) Jacobi, P. A.; Coutts, L. D.; Guo, J.; Hauck, S. I.; Leung, S. H. New Strategies for the Synthesis of Biologically Important Tetrapyrroles. The "B,C $+\mathrm{D}+\mathrm{A}$ " Approach to Linear Tetrapyrroles. J. Org. Chem. 2000, 65, 205-213.

(2) (a) Bhardwaj, V.; Gumber, D.; Abbot, V.; Dhiman, S.; Sharma, P. Pyrrole: A Resourceful Small Molecule in Key Medicinal Heteroaromatics. RSC $A d v$. 2015, 5, 15233-15266. (b) Arikawa, Y.; Nishida, H.; Kurasawa, O.; Hasuoka, A.; Hirase, K.; Inatomi, N.; Hori, Y.; Matsukawa, J.; Imanishi, A.; Kondo, M.; Tarui, N.; Hamada, T.; Takagi, T.; Takeuchi, T.; Kajino, M. Discovery of a Novel Pyrrole Derivative 1-[5-(2-Fluorophenyl)-1-(pyridin-3-ylsulfonyl)-1H-pyrrol-3-yl]$\mathrm{N}$-methylmethanamine Fumarate (TAK-438) as a PotassiumCompetitive Acid Blocker (P-CAB). J. Med. Chem. 2012, 55, 4446-4456. (c) Wang, M.-Z.; Xu, H.; Liu, T.-W.; Feng, Q.; Yu, S.-J.; Wang, S.-H.; Li, Z.-M. Design, Synthesis and Antifungal Activities of Novel Pyrrole Alkaloid Analogs. Eur. J. Med. Chem. 2011, 46, 1463 1472. (d) van Pée, K.-H.; Ligon, J. M. Biosynthesis of Pyrrolnitrin and Other Phenylpyrrole Derivatives by Bacteria. Nat. Prod. Rep. 2000, 17, 157-164.

(3) (a) Takase, M.; Yoshida, N.; Narita, T.; Fujio, T.; Nishinaga, T.; Iyoda, M. Sterically Congested Pyrrole-Fused Tetrathiafulvalene Decamers as Highly Conductive Amorphous Molecular Materials. RSC Adv. 2012, 2, 3221-3224. (b) Brothers, P. J. Boron Complexes of Pyrrolyl Ligands. Inorg. Chem. 2011, 50, 12374-12386. (c) Ulrich, G.; Ziessel, R.; Harriman, A. The Chemistry of Fluorescent Bodipy Dyes: Versatility Unsurpassed. Angew. Chem. Int. Ed. 2008, 47, 1184-1201. (d) Wood, T. E.; Thompson, A. Advances in the Chemistry of Dipyrrins and Their Complexes. Chem. Rev. 2007, 107, 18311861. (e) Loudet, A.; Burgess, K. BODIPY Dyes and Their Derivatives: Syntheses and Spectroscopic Properties. Chem. Rev. 2007, 107, 4891-4932.

(4) (a) Dipakranjan, M.; Brateen, S.; Bidyut, K. D. Pyrrole and Its Derivatives. In Heterocycles in Natural Product Synthesis; Majumdar, K. C., Chattopadhyay, S. K., Eds.; Wiley-VCH: Weinheim, 2011; pp 187-220. (b) Fan, H.; Peng, J.; Hamann, M. T.; Hu, J.-F. Lamellarins and Related Pyrrole-Derived Alkaloids from Marine Organisms. Chem. Rev. 2008, 108, 264-287.

(5) (a) Knorr, L. Synthetische Versuche mit dem Acetessigester. II. Mittheilung: Ueberführung des Diacetbernsteinsäureesters und des Acetessigesters in Pyrrolderivate. Ann. 1886, 236, 290-296.

(6) (a) Hantzsch, A. Neue Bildungsweise von Pyrrolderivaten. Ber. Dtsch. Chem. Ges. 1890, 23, 1474-1476. (b) Leonardi, M.; Estévez, V.; Villacampa, M.; Menéndez, J. C. The Hantzsch Pyrrole Synthesis: Non-Conventional Variations and Applications of a Neglected Classical Reaction. Synthesis 2019, 51, 816-828.

(7) (a) Knorr, L. Ludwig Knorr: Synthese von Pyrrolderivaten. Ber. Dtsch. Chem. Ges. 1884, 17, 1635-1642. (b) Paal, C. Synthese von Thiophen- und Pyrrolderivaten. Ber. Dtsch. Chem. Ges. 1885, 18, 367-369. (c) Zhang, L.; Zhang, J.; Ma, J.; Cheng, D.-J.; Tan, B. Highly Atroposelective Synthesis of Arylpyrroles by Catalytic Asymmetric Paal-Knorr Reaction. J. Am. Chem. Soc. 2017, 139, 1714-1717. (d) 
Kim, B. H.; Bae, S.; Go, A.; Lee, H.; Gong, C.; Lee, B. M. Synthesis of Two Distinct Pyrrole Moiety Containing Arenes from Nitroanilines using Paal-Knorr Followed by an Indium-Mediated Reaction. Org. Biomol. Chem. 2016, 14, 265-276.

(8) (a) Estévez, V.; Villacampa, M.; Menéndez, J. C. Recent Advances in the Synthesis of Pyrroles by Multicomponent Reactions. Chem. Soc. Rev. 2014, 43, 4633-4657. (b) Estévez, V.; Villacampa, M.; Menéndez, J. C. Multicomponent Reactions for the Synthesis of Pyrroles. Chem. Soc. Rev. 2010, 39, 4402-4421.

(9) For selected reviews, see: (a) Gulevich, A. V.; Dudnik, A. S. Chernyak, N.; Gevorgyan, V. Transition Metal-Mediated Synthesis of Monocyclic Aromatic Heterocycles. Chem. Rev. 2013, 113, 3084-3213. (b) Nakamura, I.; Yamamoto, Y. Transition-MetalCatalyzed Reactions in Heterocyclic Synthesis. Chem. Rev. 2004, 104 2127-2198. (c) Yoshikai, N.; Wei, Y. Synthesis of Pyrroles, Indoles, and Carbazoles through Transition-Metal-Catalyzed C-H Functionalization. Asian J. Org. Chem. 2013, 2, 466-478. For selected examples of recent publications, see: (d) Kawakita, K.; Beaumier, E. P.; Kakiuchi, Y.; Tsurugi, H.; Tonks, I. A.; Mashima, K. Bis(imido)vanadium(V)-Catalyzed $[2+2+1]$ Coupling of Alkynes and Azobenzenes Giving Multisubstituted Pyrroles. J. Am. Chem. Soc. 2019, 141, 4194-4198. (e) Li, M.-B.; Grape, E. S.; Bäckvall, J.-E. Palladium-Catalyzed Stereospecific Oxidative Cascade Reaction of Allenes for the Construction of Pyrrole Rings: Control of Reactivity and Selectivity. ACS Catal. 2019, 9, 5184-5190. (f) Chiu, H.-C.; Tonks, I. A. Trimethylsilyl-Protected Alkynes as Selective CrossCoupling Partners in Titanium-Catalyzed [2+2+1] Pyrrole Synthesis. Angew. Chem. Int. Ed. 2018, 57, 6090-6094. (g) Andreou, D. Kallitsakis, M. G.; Loukopoulos, E.; Gabriel, C.; Kostakis, G. E.; Lykakis, I. N. Copper-Promoted Regioselective Synthesis of Polysubstituted Pyrroles from Aldehydes, Amines, and Nitroalkenes via 1,2Phenyl/Alkyl Migration. J. Org. Chem. 2018, 83, 2104-2113. (h) Gilbert, Z. W.; Hue, R. J.; Tonks, I. A. Catalytic Formal $[2+2+1]$ Synthesis of Pyrroles from Alkynes and Diazenes via $\mathrm{Ti}^{\mathrm{il}} / \mathrm{TiI}^{\mathrm{V}}$ Redox Catalysis. Nat. Chem. 2016, 8, 63-68. (i) Li, X.; Chen, M.; Xie, X.; Sun, N.; Li, S.; Liu, Y. Synthesis of Multiple-Substituted Pyrroles via Gold(I)-Catalyzed Hydroamination/Cyclization Cascade. Org. Lett. 2015, 17, 2984-2987. (j) Zhu, L.; Yu, Y.; Mao, Z.; Huang, X. GoldCatalyzed Intermolecular Nitrene Transfer from $2 \mathrm{H}$-Azirines to Ynamides: A Direct Approach to Polysubstituted Pyrroles. Org. Lett. 2015, 17, 30-33. (k) Zhang, M.; Fang, X.; Neumann, H.; Beller, M. General and Regioselective Synthesis of Pyrroles via RutheniumCatalyzed Multicomponent Reactions. J. Am. Chem. Soc. 2013, 135, 11384-11388. (1) Gao, M.; He, C.; Chen, H.; Bai, R.; Cheng, B.; Lei, A. Synthesis of Pyrroles by Click Reaction: Silver-Catalyzed Cycloaddition of Terminal Alkynes with Isocyanides. Angew. Chem. Int. Ed. 2013, 52, 6958-6961.

(10) For representative examples of recent publications, see: (a) Pirnot, M. T.; Wang, Y.-M.; Buchwald, S. L. Copper Hydride Catalyzed Hydroamination of Alkenes and Alkynes. Angew. Chem. Int. Ed. 2016, 55, 48-57. (b) Miki, Y.; Hirano, K.; Satoh, T.; Miura, M. Copper-Catalyzed Intermolecular Regioselective Hydroamination of Styrenes with Polymethylhydrosiloxane and Hydroxylamines. Angew. Chem. Int. Ed. 2013, 52, 10830-10834. (c) Zhu, S.; Niljianskul, N.; Buchwald, S. L. Enantio- and Regioselective $\mathrm{CuH}-\mathrm{Catalyzed} \mathrm{Hy-}$ droamination of Alkenes. J. Am. Chem. Soc. 2013, 135, 15746-15749. (d) Saxena, A.; Choi, B.; Lam, H. W. Enantioselective CopperCatalyzed Reductive Coupling of Alkenylazaarenes with Ketones. $J$. Am. Chem. Soc. 2012, 134, 8428-8431. (e) Yang, Y.; Perry, I. B.; Lu, G.; Liu, P.; Buchwald, S. L. Copper-Catalyzed Asymmetric Addition of Olefin-Derived Nucleophiles to Ketones. Science 2016, 353 , 144-150. (f) Wang, Y.-M.; Buchwald, S. L. Enantioselective CuHCatalyzed Hydroallylation of Vinylarenes. J. Am. Chem. Soc. 2016, 138, 5024-5027. (g) Bandar, J. S.; Ascic, E.; Buchwald, S. L. Enantioselective CuH-Catalyzed Reductive Coupling of Aryl Alkenes and Activated Carboxylic Acids. J. Am. Chem. Soc. 2016, 138, 5821-5824. (h) Friis, S. D.; Pirnot, M. T.; Buchwald, S. L. Asymmetric Hydroarylation of Vinylarenes Using a Synergistic Combination of $\mathrm{CuH}$ and Pd Catalysis. J. Am. Chem. Soc. 2016, 138, 8372-8375. (i) Lee, J.; Torker, S.; Hoveyda, A. H. Versatile Homoallylic Boronates by Chemo-, $\mathrm{S}_{\mathrm{N}} 2$ '- Diastereo- and Enantioselective Catalytic Sequence of $\mathrm{Cu}-\mathrm{H}$ Addition to Vinyl-B(pin)/Allylic Substitution. Angew. Chem Int. Ed. 2017, 56, 821-826. (j) Xu, G.; Zhao, H.; Fu, B.; Cang, A.; Zhang, G.; Zhang, Q.; Xiong, T.; Zhang, Q. Ligand-Controlled Regiodivergent and Enantioselective Copper-Catalyzed Hydroallylation of Alkynes. Angew. Chem. Int. Ed. 2017, 56, 13130-13134. (k) Zhou, Y.; Bandar, J. S.; Buchwald, S. L. Enantioselective CuH-Catalyzed Hydroacylation Employing Unsaturated Carboxylic Acids as Aldehyde Surrogates. J. Am. Chem. Soc. 2017, 139, 8126-8129. (1) Gui, Y.-Y.; Hu, N.; Chen, X.-W.; Liao, L.-L.; Ju, T.; Ye, J.-H.; Zhang, Z.; Li, J.; Yu, D.-G. Highly Regio- and Enantioselective CopperCatalyzed Reductive Hydroxymethylation of Styrenes and 1,3-Dienes with $\mathrm{CO}_{2}$. J. Am. Chem. Soc. 2017, 139, 17011-17014. (m) Gribble, M. W., Jr.; Guo, S.; Buchwald, S. L. Asymmetric Cu-Catalyzed 1,4Dearomatization of Pyridines and Pyridazines without Preactivation of the Heterocycle or Nucleophile. J. Am. Chem. Soc. 2018, 140, 5057-5060. (n) Schuppe, A. W.; Borrajo-Calleja, G. M.; Buchwald, S L. Enantioselective Olefin Hydrocyanation without Cyanide. J. Am. Chem. Soc. 2019, 141, 18668-18672.

(11) (a) Lu, G.; Liu, R. Y.; Yang, Y.; Fang, C.; Lambrecht, D. S.; Buchwald, S. L.; Liu, P. Ligand-Substrate Dispersion Facilitates the Copper-Catalyzed Hydroamination of Unactivated Olefins. J. Am. Chem. Soc. 2017, 139, 16548-16555. (b) Thomas, A. A.; Speck, K.; Kevlishvili, I.; Lu, Z.; Liu, P.; Buchwald, S. L. Mechanistically Guided Design of Ligands That Significantly Improve the Efficiency of CuH-Catalyzed Hydroamination Reactions. J. Am. Chem. Soc. 2018 140, 13976-13984. (c) Yang, Y.; Perry, I. B.; Buchwald, S. L. Copper-Catalyzed Enantioselective Addition of Styrene-Derived Nucleophiles to Imines Enabled by Ligand-Controlled Chemoselective Hydrocupration. J. Am. Chem. Soc. 2016, 138, 9787-9790.

(12) For recent examples involving propargyl/allenyl copper intermediates, see: (a) Bayeh-Romero, L.; Buchwald, S. L. Copper Hydride Catalyzed Enantioselective Synthesis of Axially Chiral 1,3Disubstituted Allenes. J. Am. Chem. Soc. 2019, 141, 13788-13794. (b) Huang, Y.; del Pozo, J.; Torker, S.; Hoveyda, A. H. Enantioselective Synthesis of Trisubstituted Allenyl-B(pin) Compounds by Phosphine-Cu-Catalyzed 1,3-Enyne Hydroboration. Insights Regarding Stereochemical Integrity of $\mathrm{Cu}$-Allenyl Intermediates. J. Am. Chem. Soc. 2018, 140, 2643-2655. (c) Sang, H. L.; Yu, S.; Ge, S. CopperCatalyzed Asymmetric Hydroboration of 1,3-Enynes with Pinacolborane to Access Chiral Allenylboronates. Org. Chem. Front. 2018, 5 , 1284-1287. (d) Gao, D.-W.; Xiao, Y.; Liu, M.; Liu, Z.; Karunananda, M. K.; Chen, J. S.; Engle, K. M. Catalytic, Enantioselective Synthesis of Allenyl Boronates. ACS Catal. 2018, 8, 3650-3654. (e) Yu, S.; Sang, H. L.; Zhang, S.-Q.; Hong, X.; Ge, S. Catalytic Asymmetric Synthesis of Chiral Trisubstituted Heteroaromatic Allenes from 1,3Enynes. Commun. Chem. 2018, 1, 64-73. (f) Meng, F.; Haeffner, F.; Hoveyda, A. H. Diastereo- and Enantioselective Reactions of Bis(pinacolato)diboron, 1,3-Enynes, and Aldehydes Catalyzed by an Easily Accessible Bisphosphine-Cu Complex. J. Am. Chem. Soc. 2014, 136, 11304-11307.

(13) Zhang, S.; del Pozo, J.; Romiti, F.; Mu, Y.; Torker, S.; Hoveyda, A. H. Delayed Catalyst Function Enables Direct Enantioselective Conversion of Nitriles to $\mathrm{NH}_{2}$-Amines. Science 2019, 364, 45-51.

(14) For selected reviews on the synthesis of 1,3-enynes, see: (a) Zhou, Y.; Zhang, Y.; Wang, J. Recent Advances in Transition-MetalCatalyzed Synthesis of Conjugated Enynes. Org. Biomol. Chem. 2016, 14, 6638-6650. (b) Trost, B. M.; Masters, J. T. Transition MetalCatalyzed Couplings of Alkynes to 1,3-Enynes: Modern Methods and Synthetic Applications. Chem. Soc. Rev. 2016, 45, 2212-2238.

(15) The regioselectivities of reported examples range from 5:1 to $>20: 1$ and are determined by ${ }^{1} \mathrm{H}$ NMR spectroscopy. In some cases, the ratio is less accurate due to the overlap of signals for the two regioisomers. The two regioisomers can be well separated by silica gel chromatography. The isolated yields reported in Table 2 refer to the major products unless otherwise noted.

(16) For precedent reports on copper-catalyzed cyclization of alkynyl imine/enamine, see: (a) Kel'in, A. V.; Sromek, A. W.; Gevorgyan, V. A Novel Cu-Assisted Cycloisomerization of Alkynyl Imines: Efficient Synthesis of Pyrroles and Pyrrole-Containing Heterocycles. $J$. Am. Chem. Soc. 2001, 123, 2074-2075. (b) Martín, R.; Rodríguez Rivero, M.; Buchwald, S. L. Domino Cu-Catalyzed C-N Cou- 
pling/Hydroamidation: A Highly Efficient Synthesis of Nitrogen Heterocycles. Angew. Chem. Int. Ed. 2006, 45, 7079-7082.

(17) (a) Yang, Y.; Shi, S.-L.; Niu, D.; Liu, P.; Buchwald, S. L. Catalytic Asymmetric Hydroamination of Unactivated Internal Olefins to Aliphatic Amines. Science 2015, 349, 62-66. (b) Ye, Y.; Kim, S.-T.; Jeong, J.; Baik, M.-H.; Buchwald, S. L. CuH-Catalyzed Enantioselective Alkylation of Indole Derivatives with Ligand-Controlled Regiodivergence. J. Am. Chem. Soc. 2019, 141, 3901-3909. (c) Li, C.; Liu, R. Y.; Jesikiewicz, L. T.; Yang, Y.; Liu, P.; Buchwald, S. L. $\mathrm{CuH}-\mathrm{Catalyzed} \mathrm{Enantioselective} \mathrm{Ketone} \mathrm{Allylation} \mathrm{with} \mathrm{1,3-Dienes:}$ Scope, Mechanism, and Applications. J. Am. Chem. Soc. 2019, 141, 5062-5070.

(18) We have also located anti-addition transition states in which the benzonitrile approaches from the opposite face of the $\pi$-system and thus does not coordinate to the $\mathrm{Cu}$. These transition states are significantly higher in energy. See the SI for details.

(19) Bandar, J. S.; Pirnot, M. P.; Buchwald, S. L. Mechanistic Studies Lead to Dramatically Improved Reaction Conditions for the $\mathrm{Cu}$ -
Catalyzed Asymmetric Hydroamination of Olefins. J. Am. Chem. Soc. 2015, 137, 14812-14818.

(20) (a) Gronnier, C.; Kramer, S.; Odabachian, Y.; Gagosz, F. Cu(I)Catalyzed Oxidative Cyclization of Alkynyl Oxiranes and Oxetanes. $J$ Am. Chem. Soc. 2012, 134, 828-831. (b) Li, L.; Chen, X.-M.; Wang, Z.-S.; Zhou, B.; Liu, X.; Lu, X.; Ye, L.-W. Reversal of Regioselectivity in Catalytic Arene-Ynamide Cyclization: Direct Synthesis of Valuable Azepino[4,5-b]indoles and $\beta$-Carbolines and DFT Calculations. ACS Catal. 2017, 7, 4004-4010. (c) Li, L.; Janesko, B. G. 3Methyleneisoindolin-1-one Assembly via Base- and CuI/L-ProlineCatalyzed Domino Reaction: Mechanism of Regioselective Anionic Cyclization. J. Org. Chem. 2016, 81, 10802-10808. (d) Yuan, B.; He, R.; Shen, W.; Huang, C.; Li, M. Mechanistic Insights into the $\mathrm{Cu}(\mathrm{I})-$ and $\mathrm{Cu}(\mathrm{II})$-Catalyzed Cyclization of o-Alkynylbenzaldehydes: The Solvent DMF and Oxidation State of Copper Affect the Reaction Mechanism. J. Org. Chem. 2015, 80, 6553-6563. 


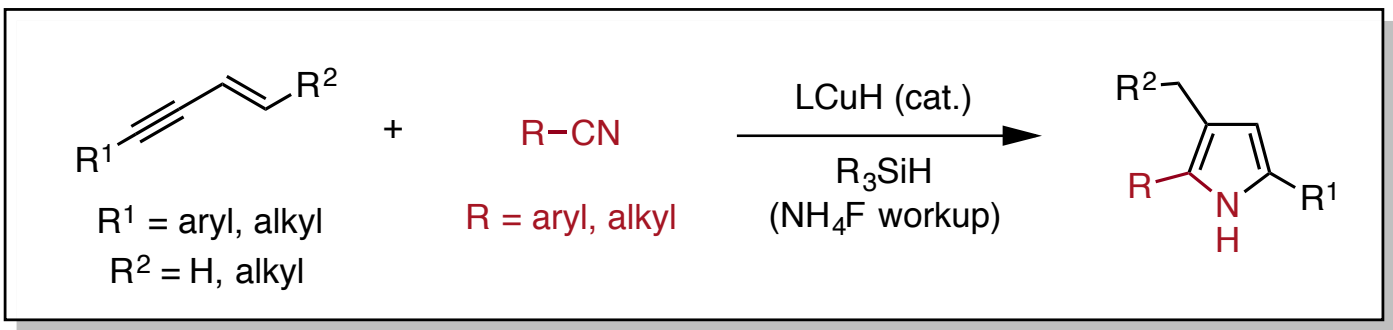

- readily accessible starting materials

- mild reaction conditions

- diverse substitution patterns accommodated

- good functional group tolerance 